\title{
COVID-19 Amongst the Ultra-Orthodox Population in Israel: An Inside Look into the Causes of the High Morbidity Rates
}

\author{
Sara Zalcberg ${ }^{1,2} \cdot$ Sima Zalcberg Block ${ }^{1,2,3}$ \\ Received: 2 December 2020 / Accepted: 15 March 2021 / Published online: 20 July 2021 \\ (C) The Author(s), under exclusive licence to Springer Nature B.V. 2021
}

\begin{abstract}
The current paper focuses on the circumstances that have led to the high COVID19 infection rates amongst the ultra-Orthodox population in Israel. The current study utilizes a qualitative design and is based on in-depth interviews, email correspondence and online records of 25 ultra-Orthodox individuals who either tested positive for COVID-19 or had contact with a verified COVID-19 patient. The data were analyzed through identification of main themes and an interpretation of their meanings. The findings showed that a wide range of causes led to the high infection rate, including aspects that derive from a structural element, a religious element and a social-ideological element-all of which are directly or indirectly connected to religion. These findings demonstrate the central role of religion in health outcomes among the ultra-Orthodox community in general and during pandemics in particular, and they shed light on the central role of religion in health outcomes among closed-religious communities. The findings further reveal the importance of cooperation between the state authorities and the religious ones, and of providing culturally adapted health service solutions in the fight against COVID-19 and promoting health more generally. Study limitations are discussed and recommendations for future research are provided.
\end{abstract}

Keywords Ultra-Orthodox · COVID-19 $\cdot$ Health behaviors $\cdot$ Social capital $\cdot$ Closedreligious communities

Sima Zalcberg Block

simazalcberg@gmail.com

Sara Zalcberg

sarazalcberg@gmail.com

1 Religion Studies, Tel Aviv University, Tel Aviv, Israel

2 Social Work, Hebrew University of Jerusalem, Jerusalem, Israel

3 Social Work, Ariel University, Ariel, Israel 


\section{Introduction}

The ultra-Orthodox population is a minority group in Israeli society and the Jewish world. In Israel, the ultra-Orthodox population is composed of over one million people who constitute $12.5 \%$ of the entire population of Israel (Malach and Cahaner 2020). Ultra-Orthodox society (also known as the Haredi community) is characterized by a strict interpretation of Jewish law, conservatism and seclusion from the majority society (Friedman 1991; Heilman 2000). In Israel, the ultra-Orthodox population has one of the highest life expectancies in the world and tend to report better health compared to the general population (Chernichovsky and Sharony 2015; Muhsen et al. 2017). Chernichovsky and Sharony (2015) explained these patterns by noting the positive relationship between measurements of high social capital-which characterize the ultra-Orthodox societyand various health-promoting aspects. Components of social capital in this context include close relations with family and friends, a high degree of community involvement, and trust in religious leaders. Moreover, the researchers refer to the positive effect that religious rituals and practices, and a faith-based worldview have on the health of ultra-Orthodox individuals. These relationships between religious aspects and health are similarly seen amongst other religious communities as well (Elgar et al. 2017; Milstein et al. 2020; Shapiro 2018; Shapiro and Chen 2018).

Nevertheless, the spread of COVID-19 in Israel in March 2020 led to particularly high infection rates amongst the ultra-Orthodox population, and during the period March-November 2020, 40\% of the total number of verified COVID-19 cases in Israel were from the ultra-Orthodox sector-a particularly high rate relative to their proportion in the population (Malach and Cahaner 2020). More so, not only were the ultra-Orthodox being infected disproportionately, they were also dying of COVID-19 at a much higher rate (Hanau 2020). It appears that the characteristics of the ultra-Orthodox community which are viewed as health-promoting (Chernichovsky and Sharony 2015), are not effective in the case of the COVID-19 pandemic. Hence, the current research sought to examine the circumstances that led to the high COVID-19 infection rates amongst the ultra-Orthodox population, based on their own perspectives. Understanding these circumstances, as they are perceived by ultra-Orthodox individuals themselves, may shed light on aspects of ultra-Orthodox society which relate both to the promotion of health and to the spread of illness. On a more general level, the findings of this study might contribute to a better understanding of the behavioral patterns of minority groups and closed-religious communities in the context of health and illness overall, and during pandemics in particular. In addition, the findings might help to create policies and plans that would decrease infection rates amongst the ultra-Orthodox population, promote culturally adapted health solutions for the ultra-Orthodox population and other similar populations, and minimize health inequalities.

To situate the current research aims within a broader context, the paper starts with a review of the link between religion and various aspects of health and 
illness. Then, a review of the ultra-Orthodox population in Israel is presented, with a focus on the cultural characteristics that are relevant for understanding the issue at hand, as well as aspects of health and illness that are unique to the ultra-Orthodox society. The research method is then specified and findings are reported. The paper concludes with a summary of the findings and specific conclusions derived from the findings.

\section{The Link Between Various Aspects of Religion, and Health and IIIness}

Religion shapes individuals' beliefs and norms, which subsequently affect health behaviors. Religion further influences the social and economic systems that generate conditions for health and illness (Milstein et al. 2020; VanderWeele 2017). Most of the recent studies have indicated a positive relationship between various aspects of religion and various aspects of health promotion and disease prevention (Krause 2016; Levin 2016; Idler and Kellehear 2017; Shapiro 2018). Many studies refer specifically to the role of social capital elements that are embedded in religion, in the promotion of health, while emphasizing the role of clergy, religious institutions, religious affiliations, inter-communal welfare, and networking, in promoting health behaviors and improving health amongst religious believers (Elgar et al. 2017; Eriksson 2011; Milstein et al. 2020; Satariano 2020; Shapiro and Chen 2018). Additional aspects of religion that are also believed to contribute to health promotion are faith, trust in God, and participation in religious practices and rituals. These factors provide meaning, promote mental health, relieve stress, increase hope, and provide consolation (Heidari et al. 2017; Levin 2016; Shapiro et al. 2020). Thus, it is not surprising that a positive link has been found between religiosity and life expectancy (Idler et al. 2017; Ofstedal et al. 2019).

Other important factors to consider in relation to religion and health are perceptions, behaviors, and access to health-related information. In this context, it should be noted that religious leaders play a significant role in shaping believers' perceptions in ways that affect health promotion (Heward-Mills et al. 2018; Saban et al. 2020; Shapiro and Chen 2018), including during the COVID-19 pandemic (FreiLandau 2020; Shapiro et al. 2020). Moreover, religious leaders influence believers' access to health-related information. This access is crucial because as information becomes more accessible, there is a greater likelihood for individuals to be exposed to health-promoting behaviors and vice versa (Peles et al. 2018).

Further, socioeconomic status is also believed to be a very significant factor that affects health behaviors and health (Cheng and Goodman 2015; Elgar et al. 2017; Wi et al. 2016). The literature has shown that higher levels of income and higher levels of education correlate with longer life expectancy and better health, and that this correlation can be found across the socioeconomic spectrum (Kail et al. 2019). In light of the connection between religion and socioeconomic status, as indicated by Weber (1964) and other theoreticians and researchers (Fisher 2020), socioeconomic status may be another significant factor related to religion that has significant health-related implications. 
The various aspects of religion that affect the health of religious believers, as aforementioned, are present in ultra-Orthodox society. The following section will focus on this particular population and describe ultra-Orthodoxy in Israel in greater detail.

\section{The Ultra-Orthodox Society in Israel: Background and Characteristics}

The ultra-Orthodox population in Israel is characterized by a particularly high fertility rate (an average of 7.1 children per ultra-Orthodox woman vs. an average of less than two children per woman in the Western world), high poverty rates (half of the ultra-Orthodox population lives under the poverty line vs. $21 \%$ of the general population), and a low rate of people with higher (secular) education (5.3\% of the ultraOrthodox population attend college and university vs. $35 \%$ of the general population) (Cahaner and Malach 2019). Moreover, population density, which is affected by the density of apartments, density of houses in the neighborhood and amount of public areas, is three to four times greater in ultra-Orthodox neighborhoods compared to the national average in non-ultra-Orthodox neighborhoods (Tsachor-Shai and Kasir 2020).

Further, the ultra-Orthodox population espouses a number of shared attributes including following the strictest interpretation of the Jewish law, commitment to Torah study, obedience to religious authority, gender separation and following strict modesty roles, objection to or reservations about Zionism, and a perception of the external world as threatening the community's existence (Brown 2017; Friedman 1991). These attributes contribute to the tendency of the ultra-Orthodox community to isolate itself and avoid cooperation with state institutions. Over time, this isolation and lack of cooperation has led to the inherent tension between the ultra-Orthodox population and the surrounding majority population.

Despite the fact that these attributes largely define the ultra-Orthodox population, the ultra-Orthodox society is not monolithic, rather it includes a wide range of streams and groups which differ from one another in their levels of commitment to tradition, as well as in practical, ritualistic and ideological aspects (Brown 2017; Friedman 1991). The literature differentiates between three main streams: (1) Hasidim, whose society is organized around a Hasidic "court" that is led by the Rebbè, otherwise known as the Admor, who guides the Hasidim and shapes the nature of his congregation; (2) Lithuanian Jews, who cling to the ethos of the Society of Scholars that emphasize its sons' devotion to Torah study (Friedman 1991); and (3) Sephardim, a stream comprised of oriental Jews who have adopted a new Sephardic-oriental religious identity with its own rituals, which was formed through Rabbi Ovadia Yossef's rulings with the help of the Shas party. The Lithuanian stream is characterized by a relative openness to modern life as compared to the Hasidic stream. The Sephardic group has adopted the Lithuanian religious model, though it is characterized by a less strict approach to most areas of life (Brown 2017; Friedman 1991).

The literature also distinguishes between the mainstream moderate camp of ultra-Orthodox society - which comprises the majority of the ultra-Orthodox in Israel-and the zealot groups (Kanaim), which constitute a minority within the 
ultra-Orthodox population (Caplan 2017). The mainstream camp, despite its original reservations about the establishment of a Jewish state and the tension that exists with the ruling group in the State of Israel, has acknowledged the existence of the State of Israel since its establishment, and is significantly represented in the political arena (Brown 2017). This camp tends to follow the state's laws and avoids clashes with state authorities. In contrast, the zealot camp does not acknowledge the State of Israel as a Jewish state, and some of its affiliated groups have tended to break state laws in a provocative and violent way throughout the years (Ben Yehuda 2010; Friedman 2002).

In the past two decades, an "Israelization" trend has been detected within the moderate camp, i.e. an increasing integration with the majority society across various aspects of life and an adoption of modern perceptions and values (Braun-Lewensohn and Kalagy 2019; Caplan and Stadler 2009; Malach and Cahaner 2020). These changes have led to a gradual increase in cooperation with state institutions among the ultra-Orthodox population, even including some of the zealot circles (Zalcberg 2021).

These changes, along with growing factions within the ultra-Orthodox community-with the deaths of G'dolei Hador ("greatest of the generation") during the last two decades - have led to a leadership crisis within the ultra-Orthodox society. This crisis led to a development of sub-authorities that slightly cracked the traditional religious authorities (Brown 2017).

\section{Health Behaviors in the Ultra-Orthodox Society}

The ultra-Orthodox population in Israel engages in low levels of health-promoting behaviors (Chernichovsky and Sharony 2015), which is similar to other populations that are characterized by low levels of education and a low socioeconomic status (Aue et al. 2016). As a result of the poor economic situation of many ultra-Orthodox families, they typically do not have enough money to buy fresh fruits and vegetables. Along with a lack of fresh produce, they also tend to lack awareness of the importance of healthy nutrition and do not engage in physical exercise. Altogether, these limitations have contributed to a higher percentage of overweight individuals in the ultra-Orthodox population as compared to the secular population (Bayram and Donchin 2019; Leiter et al. 2019).

In addition, the limited knowledge within the ultra-Orthodox population regarding diseases and the importance of early detection affects their health behaviors (Zalcberg Block 2014). On certain topics, their lack of knowledge could be a result of taboos, mainly when the topic relates to "immodest organs" (Zalcberg 2009). For instance, ultra-Orthodox women are significantly less aware of breast cancer and early detection tests than are non-ultra-Orthodox women, which consequently results in lower rates of testing for ultra-Orthodox women (Pinchas-Mizrachi et al. 2020). Further, the rate of people who waive medical treatments in ultra-Orthodox society is higher than the rate amongst the majority society; this discrepancy is also due to income gaps between the two groups (Kasir et al. 2017). 
In addition to the influences of health awareness and the economic situation on the health behaviors and health outcomes of ultra-Orthodox individuals, there is the influence of religious leaders, which are the Rabbis and Admors (Peles et al. 2018; Zalcberg Block 2014), and the "health mediators"-figures in the community who are perceived as alternative authorities on health-related decisions (Coleman Brueckheimer et al. 2009). The latter mediate between the ultra-Orthodox people and the health professionals and service providers outside of the ultra-Orthodox world.

While the ultra-Orthodox population demonstrates a low level of health-promoting behaviors, its members are characterized with aspects known to be health-promoting, such as high social capital, religious rituals and practices, and a faith-based worldview (Chernichovsky and Sharony 2015). In addition, a recent study shows that the ultra-Orthodox have lower mortality than other Israelis despite lower socioeconomic status (Pinchas-Mizrachi et al. 2020). In light of this, questions regarding the circumstances that led to the high morbidity rates of COVID-19 among the ultra-Orthodox population and regarding the place of its health-promoting aspects in this context become more acute.

\section{The Research Method}

\section{Research Paradigm}

In order to better understand the circumstances that led to the broad spread of COVID-19 virus amongst the ultra-Orthodox population in Israel, the current study focused on the perspectives of individuals within the ultra-Orthodox community who tested positive for COVID-19 or had contact with a verified patient. The study utilized a qualitative paradigm (Denzin and Lincoln 2011) which focused on the reality as it is perceived by those who are living it. This approach allows for gaining insights about participants' experiences through their unique social-cultural context and the significance that they attach to those experiences.

\section{Sample and Sampling Method}

The study sample included men and women from various Ashkenazi groups of ultraOrthodox society (from the Lithuanian stream and the Hasidic stream) who were over the age of 18, who tested positive for COVID-19 or had contact with a verified COVID-19 patient, and who expressed willingness to share their knowledge and perceptions regarding the research topic. The sample included only people who tested positive for COVID-19 or had contact with a verified COVID-19 patient because the researchers wanted to get the point of view of people who had or whose families had to cope with the COVID-19 virus and its implications for the close environment. Since the ultra-Orthodox Sephardim are considered more open towards majority society and more cooperative with state authorities, they were excluded from this study. 
The study was conducted using "purposeful sampling," an approach in which participants are selected on the basis of being able to provide an answer to the research question due to their connection to the research topic and their knowledge of the studied phenomenon (Emmel 2013). In order to recruit participants, the researchers reached out to their contacts from the ultra-Orthodox community who were known to them from previous studies they conducted on ultra-Orthodox society. These contacts helped in recruiting participants for the current study. At a later stage, some of the participants referred the researchers to additional participants ("snowball sampling"). The final sample included 25 participants (17 men, 8 women), age range 25-60. Eleven of them had tested positive for COVID-19, and the others had contact with a verified COVID-19 patient. All participants were married, and the mean number of children per participant was seven. Ten of the participants were from the Lithuanian stream and the rest were Hasidic. All lived in urban areas. Two-thirds of the participants worked in the field of education and social work.

\section{Data Collection}

Data collection primarily consisted of semi-structured in-depth interviews conducted in Hebrew. The interviews were based on an interview guide that included the following topics: personal and familial coping with the COVID-19 pandemic and the Ministry of Health's $(\mathrm{MOH})$ instructions; perceptions regarding the way the ultra-Orthodox community and its religious leadership cope with the pandemic and the MOH's instructions; and perceptions regarding the way the government and authorities cope with the spread of the pandemic. The interview guide was formed based on previous studies that focused on aspects related to welfare and health in the ultra-Orthodox population, as well as ultra-Orthodox individuals' attitudes toward the state authorities (Zalcberg 2013; Zalcberg Block 2020). Twenty participants completed these interviews by phone. Each interview lasted between 1 and 1.5 hours. For the remaining five participants, data were collected through email correspondence and messaging (WhatsApp chats). The data collection started in March 2020 and ended in September 2020. With participants' consent, all interviews were documented in writing and some (15) were recorded and transcribed. Only five interviews were not recorded according to the participants' preference.

\section{Data Analysis}

Data analysis was based on the grounded theory approach (Corbin and Strauss 2015), which is relevant for studies in which there is a general research question without a hypothesis to prove or disprove, as in the current study. The analysis, according to this approach, consists of two levels: The first is a general thematic analysis to identify major themes in the interviews and correspondence, and the second consists of uncovering the meanings underlying the surface-level data, as well as the meanings of the first-level categories. 


\section{Quality Assurance and Ethical Aspects}

The study's quality assurance was based on Lincoln and Guba's criteria of qualitative research (Lincoln and Guba 1985). Credibility of the findings was established by including participants from various ultra-Orthodox groups in order to reach a broad range of opinions on the subject; usage of an in-depth interview to encourage free and open dialogue; repetitive review of data collection and analysis processes; and engagement in a peer review process of the findings, with implementation of recommendations. Further, to reduce researcher bias, there was an explicit focus on having the researchers be aware of their own perceptions about the study topic and an explicit effort to avoid guiding participants to discuss particular topics during the interview. This step supported the conformability of the findings. The transferability of findings was demonstrated by the inclusion of a detailed description of the study's participants, the research process and an explanation of how the findings fit within the relevant cultural context.

The study was conducted in accordance with the code of ethics as determined by the American Psychological Association (2002). As such, the study's purpose was explained to participants prior to the start of the study. Participation was voluntary, and participants were notified that they would be able to withdraw from the study at any given time. Participants' confidentiality and anonymity were ensured throughout all stages of the study and included the use of pseudonyms and the omission of all identifying details from the current paper.

\section{Findings}

The data analysis revealed three main factors that participants perceived as causes for the high COVID-19 infection rate amongst the ultra-Orthodox population: (1) population and housing density; (2) community way of life; and (3) disobedience of the MOH's instructions of social distancing, isolation (when necessary), and wearing of face masks.

\section{Population and Housing Density}

One of the main factors that most participants mentioned as having a major effect on the high infection rates amongst the ultra-Orthodox community is the demographic growth inherent in the ultra-Orthodox population (Cahaner and Malach 2019), which goes alongside the poor economic situation of ultra-Orthodox families. The combination of the two, in the eyes of the participants, led to residential density in ultra-Orthodox neighborhoods (Alfasi et al. 2013) which, in turn, did not allow for the social distancing required to prevent the spread of the virus and made it almost impossible to follow isolation instructions. 
The high degree of density is particularly evident within the family housing unit, which led to severe consequences with respect to the health of family members. Isaac, a father of seven children described:

There are nine people living in my home, a 75 cubic meters apartment. There are two bedrooms-one for the parents, one for the children, and the rest [sleep] in the living room. When my daughter was asked to stay in quarantine because she had had contact with a verified patient, I sealed part of the house with a sheet of nylon and this is where she stayed because we could not offer her a room to stay in.

The situation in Yossef's family was even worse. Yossef is a father of 10 children, and he was asked to stay in quarantine with two of his sons, but he was not able do so because of their living conditions. According to Yossef:

We were told to go into quarantine, but we had nowhere to go to. Our apartment is so tiny that all members of the family, except for the married children, had to go into quarantine together. As a result, my two sons and I infected my wife and some of the other children.

Batia, a mother of nine children, clearly expressed the implications of population density: "Many kids, many schools, and a high level of infecting, especially at home." Population and housing density had implications outside of the family housing unit as well, as explained by Batia:

In an ultra-Orthodox neighborhood, let's say in Betar-Elit [an ultra-Orthodox town], there are 8-9 floor buildings. There are at least four families on each floor. [As a result] there are about 30-40 apartments that use a single elevator. There are dozens of similar buildings adjacent to one another. Once there is someone who has the virus but is not yet verified as a patient and does not follow the rules [of social distancing] - he infects everybody.

The high degree of density was evident outside the apartment buildings as well-for example, in the shops and commercial centers in ultra-Orthodox neighborhoods - and thereby, inevitably affected the health of the ultra-Orthodox community at large. Ester explained:

If, in Tel-Aviv, there are a few people in a grocery shop at any given moment, here, in the grocery shop there are dozens of people together. [...] obviously, the pace of spread here is much higher. One patient sends dozens or even hundreds into quarantine.

The participants' words are in line with studies that indicate the increased likelihood of getting infected with COVID-19 amongst populations who live in dense conditions and amongst ethnic minorities in particular (Raifman and Raifman 2020). 


\section{Community Way of Life}

Another reason that many participants indicated for the high rates of COVID19 in the ultra-Orthodox community was described by Chaim as a "community cause." According to Chaim, the ultra-Orthodox society is characterized by a very "community" style of living, which includes frequent community activities: "Ultra-Orthodox people often gather together which increases the spread of the virus: three prayers a day, Torah classes, interaction with many people." In typical times, the community way of living is demonstrated through joint prayers at the synagogue, which necessitate a minimum of 10 people, but usually the number is much higher, especially on the Sabbath (Saturdays) and holidays. The number of prayers in the same dense compound can even reach hundreds or thousands, especially in the bigger congregations. Yisrael, who belongs to one of the Hasidic "closed courts" described: "There was one sick person in the synagogue and because of him 200 Hasidim were sent to quarantine."

The synagogues also serve as places for Torah study and for lectures, activities which numerous people attend. The Hasidic "Tish" is also conducted at the synagogue. The Hasidim use the word "Tish" (the word for "table" in Yiddish) to describe the gathering of Hasidim around their Rebbè while he is eating his Sabbath or holiday meal or conducting a celebration. During the Tish, the Hasidim dance and sing together and receive "Shirayim"- "leftovers" from the Rebbè which are usually small portions of the Rebbè's Challah (twist bread)—which are precious to them ( $S^{\prime}$ gula). For these reasons, explains Yisrael:

The Tish serves as a celebration for the virus. Everybody is close together. In addition, the Rebbè's "Shirayim" are touched by everyone-they pass these portions of Challah around and then put them in their mouths. In such circumstances, the virus spreads rapidly. In the women's gallery, the women stand very close to each other in order to get as close as possible to the screen and see what is happening in the men's section.

An additional major aspect of the community way of life in ultra-Orthodox society is the collective participation of community members in various rites of passage-e.g., circumcision ceremonies, bar mitzvahs and large weddings, as well as funerals and Shiva (seven-day mourning period after someone's death). As Yeshayahu described: "During the Shiva of my father, the whole neighborhood arrived. One of the consolers had COVID-19 and he infected at least 10 people." Shmuel added: "Today I attended the funeral of the Rebbè from Pittsburgh who died from COVID-19. There were hundreds of Hasidim there, next to one another, and some of them did not wear masks."

In this context, it should be noted that the pandemic broke out in Israel just before the holiday of Purim, during which many activities take place in ultraOrthodox communities. Among those activities were community gatherings in synagogues, where the Book of Esther was read; mass celebrations and Tishes; gatherings where people give each other Mishloach Manot (gift baskets consisting 
of food and drinks); and holiday feasts, which are attended by many family members. Leah, a mother of 10 children who has many grandchildren described:

I invited the family for the Purim feast. We did not know that two of the grandchildren had COVID-19. You can imagine what happened... At least half of the people who participated in the feast got infected. We went to our neighbors to give them the Mishloach Manot and we infected them as well. We were not aware of the virus at the time. On Saturday, we went to the synagogue and we infected people there as well; it was an endless cycle.

The perception of the participants regarding these aspects can be encapsulated in the description given by Abraham, as the "habitus of living together, an ethos of community," an ethos that it is almost impossible to disconnect from their way of life, as he continued, "It's like breaking up a family."

\section{Disobedience of MOH's Instructions}

The community behaviors described represent a full or partial clear violation of the Ministry of Health's guidelines for social distance and isolation during the pandemic. Continuing such behaviors was considered by the participants to be another central cause for the high infection rates. According to them, the violation of guidelines derived mainly from the following reasons: a lack of updated information about the COVID-19 pandemic and $\mathrm{MOH}$ instructions; the ultra-Orthodox population's tendency to obey instructions from the religious authorities which, in the case of COVID-19, clashed with the MOH's instructions; the perception that Torah study protects against the disease; the perception of the instructions as discriminatory against the ultra-Orthodox and unreliable; the desire to express opposition to the state and its institutions; and inappropriate conditions that ultra-Orthodox people were provided in COVID-19 facilities. Each of these reasons are described in further detail below.

\section{Lack of Relevant Information}

Many ultra-Orthodox people did not follow the instructions because of a lack of information, especially during the first wave of COVID-19. As Moyshe explained, "We only knew that we were not allowed to shake hands with the Rebbè and that we should wash our hands. The Rebbè said that we should not shake his hands and we were very strict about it." Tova, who tested positive for COVID-19 said:

We sent the children to the cheder [elementary school for ultra-Orthodox boys] because the studies continued as usual. They [the Rabbis] told us that it [COVID-19] does not harm children. One day, my son came back from the cheder and did not feel well. He had a fever and coughed a little. We did not think it was serious. Then, he improved but I started feeling funny. I started coughing and, a few days later, my temperature went up. A week later, I 
started thinking it might be connected to COVID-19 and another son of mine got infected as well.

Moyshe and Tova's words demonstrate that there was a lack of knowledge regarding required social distancing, children as vectors of transmission, identification of COVID-19 symptoms, as well as what should be done once symptoms appeared. The lack of information that the participants described stems from the tendency in this population to avoid exposure to various types of "secular" media, including the internet (Malach and Cahaner 2017). This is an important part of their efforts to isolate themselves from secular society, in order to minimize external influences. Chaim explained:

Since we do not watch TV and do not use the internet, we didn't have a clue about what we were supposed to do and what we were supposed to avoid. I, personally, have a mobile phone, but it's a Kosher phone ${ }^{1}$ - it has no access to the internet or the news.

The avoidance of "outside information" typically characterizes the closed Hasidic sect and the zealot streams; as such, many of their members were not exposed to essential information about COVID-19. Moreover, ultra-Orthodox communities have inter-community communication channels through which "outside" information is selectively conveyed, in accordance with the instructions given by religious authority figures, some of whom deliberately avoided distribution of updated, reliable information about COVID-19 for reasons that are specified in the following section. Hence, many members of the ultra-Orthodox community were unaware of information regarding the spread of COVID-19 and ways of protecting against it, and did not realize that they were endangering themselves and the people around them as they continued to attend school, Yeshivas, synagogues and family and community gatherings.

\section{Obedience to Religious Authority}

Many participants explained that although part of the ultra-Orthodox population did not have access to information-namely the ways in which the disease spreads, social distancing guidelines, and the risks associated with violating the guidelines - a considerable portion of the population was, in fact, aware of this information. Approximately half of the ultra-Orthodox population, especially those who belong to more moderate groups, use online media (Cahaner and Malach 2019) and therefore were exposed to the updated information provided through those channels. Despite that knowledge, many of them chose not to follow the MOH's guidelines entirely. Participants explained that the reason why guidelines were defied was because, among the ultra-Orthodox population,

\footnotetext{
1 Kosher phones are mobile phones, which are widely used by the ultra-Orthodox people. Such devices are mainly intended for making calls, and do not have features found in most mobile devices-such as web surfing nor the use of Internet-based applications.
} 
the religious authorities (i.e., Rabbis and Admors) are to be obeyed. In the case of COVID-19, the instructions provided by the religious authorities clashed with those given by the MOH. Shimon, a social entrepreneur and a media figure from the Lithuanian stream, explained:

You see me-a modern person who has common sense and does not want to endanger himself or his family. Despite that, and despite the fact that I knew how dangerous COVID-19 might be, if Rabbi Kanievsky says that we should keep on going to the Yeshivas and sending our kids to schools, that's what I do, and it is exactly what I did today. You need to understand one thing: for an ultra-Orthodox person, even things that do not make any sense, if they are expressed by a great Rabbi, there is no doubt. If Rabbi Kanievsky tells me it's midnight now, although it's daytime and the sun is shining, and it makes no sense whatsoever, I will still believe him without any doubts.

Shimon referred to the ruling of the esteemed Rabbi of the Lithuanian communityRabbi Haim Kanievsky — who, at the beginning of the first wave of COVID-19, urged his followers to keep on studying in the Yeshivas as usual. Shimon's words, similar to explanations given by other participants, demonstrated the crucial influence of the rabbinical authority and the full obedience of the Lithuanian community to their great rabbis. The rabbis' influence extends beyond circumstances that relate to the Jewish law, and includes matters of everyday life as well (Heilman 2000; Heilman and Friedman 2010). Obeying the Great Torah Sages in regard to such matters is called "Da' as Torah," and it is considered to be a supreme value in ultra-Orthodox society (Brown 2017), even if instructions clash with believers' own common sense, their knowledge on a particular subject, or instructions provided by medical and governmental authorities. According to participants, this value guided the behavior of many members of the Lithuanian community, most of whom affiliate with the moderate mainstream camp of ultra-Orthodox society. Despite the fact that members of this community have a relatively modern worldview, tend to obey state authorities and laws, and have some exposure to "secular" media (Malach and Cahaner 2017), the instructions given by Rabbi Kanievsky led many of them to continue attending Yeshivas and sending their children to schools. These behaviors were in explicit violation of the MOH's guidelines, and according to participants, engagement in them eventually led to increased infection rates in these communities.

Similar ideas were voiced by participants from the Hasidic stream. This stream is guided by "Emunat Chachamim" ("faith of sages"), wherein members believe in the wisdom and power of their Admors in contexts that extend beyond the teachings of Jewish law (Brown 2017; Heilman and Friedman 2010). Shmuel, who belongs to one of the largest Hasidic sects in Jerusalem, said:

The ideal, according to my Hasidic perspective, is that I am committed to God even if he orders me to do something that contradicts my common sense. God orders me to listen to my Rebbè because the Rebbè is a spiritual force who is knowledgeable about Torah and knows how to interpret it; he relies on the law of God and the law of Torah. I, as a religious person, see his words as a divine order. If the Rebbè says something, we will follow him no matter what. That is 
why if the Rebbè says everybody can pray together, that's what we'll do, even though the $\mathrm{MOH}$ says the opposite.

Aaron, who also affiliates with the Hasidic stream, had a similar perspective to Shmuel: "In the eyes of the Hasid, the Admor is superior to the prime minister, the Supreme Court and the inspector general of the police." For that reason, as Shmuel goes on to explain, "All of the Hasidim accepted the Rebbès' invitation to his grandson's wedding. They all came to the wedding, danced, and were joyful." All this, despite the fact that there were thousands of guests, which was clearly a violation of social distancing guidelines.

The concept of "Emunat Chachamim," which came to include the obligation to obey "Da'as Torah" (Brown 2017), instructs the ultra-Orthodox to obey the religious authority, rabbis and Admors with regard to their conduct during the COVID19 pandemic even in matters not related to Jewish law, and even when instructions contradicted those given by the state authorities and endangered their health and the health of those around them.

\section{Trust in the Power of the Torah}

One of the major practical implications of obeying social distancing guidelines was the shutting down of the Yeshivas, which are the primary centers in which the ultra-Orthodox people conduct Torah study. However, some participants indicated that the study of the Torah, in and of itself, would serve to protect them against the disease; as such, in order to continue studying the Torah, they needed to violate the MOH's guidelines. Aaron, who disobeyed social distancing rules by attending Yeshiva, explained:

The study of the Torah is the oxygen pipe of the Jewish people and oxygen pipes are not disconnected in emergencies. The Torah helped our nation to recover after the Holocaust. As it says in the Babylonian Talmud, "Learning Torah protects and saves the Jewish people."

Since the Torah is thought to protect the Jewish people against any possible threats, and since Yeshivas are the major places in which the Torah is studied (Friedman 1991), participants explained that Yeshivas constitute the source of power for the people of Israel. As Aaron said, "shutting Yeshivas down would be equal to killing - an act that is far more dangerous than potential infection." This perspective guided the behavior of the rabbinical leadership, as well as many people within the ultra-Orthodox population, who continued to attend Yeshivas and send their children to schools as usual. Such behaviors, according to participants, inevitably led to high infection rates within the ultra-Orthodox population.

\section{Perceiving Instructions as Unreliable and Discriminating}

Another explanation that arose among many of the participants for the disobedience of $\mathrm{MOH}$ guidelines among parts of the ultra-Orthodox population was the 
sense of ambiguity of the guidelines. This ambiguity was particularly salient during the second wave of COVID-19, especially surrounding the MOH's orders to avoid mass prayers during the holidays and the near shut down of synagogues. As Nahman explained:

Ultra-orthodox people do not disregard the verse: "But you should take great care for your souls" [Deuteronomy, 4:15]; however, they disagree with the manner in which the $\mathrm{MOH}$ interprets it. Because we see the protests [against the prime minister] occurring on Balfour Street, and we see that nobody condemns what is happening there and that people completely disregard the verse, we come to understand that there is no connection between the state's instructions and protecting oneself from the disease; thus, we assume that the synagogues can remain open despite the state's prohibition. We do not take human lives lightly, but we have a different idea of how the situation should be handled.

Some of the participants were truly under the impression that the instructions given by the authorities were unreliable since, according to them, they addressed only a portion of the population. Specifically, participants referred to the orders to shut down synagogues and Yeshivas-which affected their communitieswhereas no orders were given to prohibit the secular population from participating in mass protests against the prime minister. Moreover, some participants defined it as blatant discrimination, or even the persecution of the ultra-Orthodox population. Dina explained, "The discrimination against the ultra-Orthodox population, which is embedded in the MOH's instructions, undermines our trust in the instructions." Such sentiments had not simply appeared, rather they were the result of the inherent tension that has existed between the ultra-Orthodox population and the surrounding majority society ever since the establishment of the State of Israel, as well as the overall suspicion of the ultra-Orthodox population concerning state laws. As Aaron explained:

Since the establishment of the State, the ultra-Orthodox society has been suspicious of any instructions given by the authorities. We feel that "they are looking for us" [...]. And now, with COVID-19, it is really obvious. Here, they opened a pet store-why are pet stores more important than synagogues? People are allowed to walk their dogs, to jog and to attend protests, but we are not allowed to go to the synagogue. Do you understand the significance of a synagogue? Do you understand what a closed synagogue means to an ultra-Orthodox person?

Allowing mass protests, on the one hand, and shutting down synagogues and Yeshivas, on the other hand, made many members of the ultra-Orthodox community, as well as some of the religious leaders, feel that the State "prefers one value over another," as Shmuel explained. Shmuel continued to note that, "Freedom of speech is more important to them than other values, our values. They are not familiar with the values of the ultra-Orthodox community and do not know how to treat us, which leads us to have strong feelings of suspicion." 


\section{Defiance Against the Establishment}

An intentional and pronounced violation of the MOH's guidelines was particularly evident within the zealot groups. Ever since the British mandate, these groups have adopted an extreme, uncompromising anti-Zionist approach and ordered their members to distinguish themselves from the Zionist enterprise and the State of Israel. As a result, the zealot groups do not acknowledge the State of Israel as a Jewish state and refuse to cooperate with its institutions. These groups are characterized by a militant, activist approach and frequently initiate clashes with state authorities (Caplan 2017; Friedman 1991).

Once the instructions that prohibited large gatherings were published, some of the zealot groups seized the opportunity to express their opposition to the State by explicitly violating the instructions and initiating mass gatherings. When a lockdown of ultra-Orthodox neighborhoods was declared, these groups blatantly and provocatively broke it, while exercising violence against law enforcement officials. Shlomi, a member of one of the extremist groups, explained, "You and your army, and your police force will not tell us what to do and how to behave. The State of Israel has turned into a dictatorship. Why are they interfering with our lives? We obey the Lord only." Similarly, Aaron added: "We are a state within a state. We have our own laws; we do not obey your laws."

\section{Inappropriate Conditions in COVID-19 Facilities}

According to the $\mathrm{MOH}$, under certain circumstances, those diagnosed with COVID19 should be referred to COVID-19 facilities (mostly hotels that accommodated only COVID-19 patients during the pandemic). Among other reasons, such referrals occurred in cases in which patients might endanger their families if they continued to live under the same roof. In light of the living conditions of most members of the ultra-Orthodox population, which do not allow for proper isolation, many of them were referred to COVID-19 facilities. Yet a few participants claimed that many of the ultra-Orthodox people who were referred to the facilities refused to go due to the conditions in the facilities, which were not properly adapted to the needs of the ultraOrthodox people. Ester, who stayed in such a facility for many days said, "They did not consider the needs of an ultra-Orthodox person, which are different than those of a secular person. The atmosphere in these hotels clashed with the ultra-Orthodox way of life." Some of the participants referred to the lack of gender separation and to the immodesty displayed among the secular patients in public areas of the facilities, in addition to issues surrounding Kosher standards of the food served. Nahman, whose brother stayed for a long period of time in such a facility, explained:

Many people in the hotel wore immodest clothes and the ultra-Orthodox people felt uncomfortable. There were places where the food that was served was not Kosher enough, and the whole atmosphere was inappropriate, especially on the Sabbath, a time during which ultra-Orthodox people are used to a special Sabbath atmosphere. 


\section{Summary and Conclusions}

The findings of this study point to a wide range of causes that led to the high infection rates amongst the ultra-Orthodox population, as perceived by participants. Some of these causes relate to what can be termed the structural element. This element refers to aspects that are built-in to the ultra-Orthodox society, such as population and housing density, a community way of living, and a lack of exposure to external information. Other causes relate to what can be termed the religious element. This element refers to the tendency of ultra-Orthodox people to obey religious authorities even if their instructions clash with the MOH's instructions; the ultra-Orthodox people's trust in the power of the Torah to protect them from diseases, which led to the continuation of studies in the Yeshivas; and the refusal to be moved to COVID19 facilities in light of the "secular" conditions. Other causes relate to what can be termed the social-ideological element. This element encompasses explicit violations of the MOH's instructions among the ultra-Orthodox population, both because they were perceived to be discriminatory against them and because the very act of violating official instructions was an expression of defiance against the State and its authorities and institutions.

Some of these causes were mentioned by the majority of participants, whereas others were mentioned by only a few of them. This fact reflects the multiple perspectives of the participants regarding the subject, and it can point to the lack of unanimity among the ultra-Orthodox population, and the diversity of opinions that exists across the various ultra-Orthodox groups, concerning ways of dealing with the pandemic. This finding is highly significant as it indicates that there is no "unified front" among the ultra-Orthodox sector against state authorities and the MOH's instructions, contrary to the discourse that has developed in the Israeli media over the past few months. ${ }^{2}$

The fact that participants explained the high infection rates as related to the structural element of ultra-Orthodox society indicates that the spread of the pandemicat least in parts of the ultra-Orthodox population during the initial stages-was not a result of intentional behavior on the part of the ultra-Orthodox people, but rather an outcome of their living conditions and lifestyle.

Although different participants mentioned different circumstances, which they thought led to the high infection rates, all of the circumstances mentioned had a common denominator-a religious component. Even the causes that were not directly related to the religious element were indirectly associated with a religious component. For example, causes related to the structural element, such as population and housing density, result from large families which is rooted in the commandment to procreate ("be fruitful and multiply"; Genesis 1:28), as well as the emphasis on the values of a modest and simple lifestyle and a focus on spirit rather than material. Likewise, the community way of life derives from, among other reasons, frequent religious practices that require a quorum of at least 10 men (a minyan).

\footnotetext{
${ }^{2}$ For example see: https://www.haaretz.co.il/health/corona/.premium.HIGHLIGHT-1.9221075
} 
Further, the avoidance of external information is a purposeful separation mechanism to minimize influence from the secular world in order to preserve the traditional way of life (Heilman 2000). Even causes related to the social-ideological element have a clear religious affinity, as they are an outcome of the long-standing inherent tension between ultra-Orthodox society and the majority society, and are rooted in religious objections to the establishment of the Jewish State and its "secular" nature (Friedman 1991; Brown 2017).

The fact that participants' responses about what led to high COVID-19 infection rates amongst the ultra-Orthodox population were clearly linked to religion attests to the significant role that religion plays in the health behaviors and health status of ultra-Orthodox people. This conclusion is in line with the literature on the role religion plays in believers' health behaviors and health status (Krause 2016; Levin 2016; VanderWeele 2017). However, whereas many studies have emphasized the positive relationship between various aspects of religion (social capital, participation in religious practices, a faith-based worldview) and health promotion (Chernichovsky and Sharony 2015; Elgar et al. 2017; Milstein et al. 2020; Satariano 2020; Shapiro et al. 2020), the findings of the current study presented a different picture. The current study demonstrated that some aspects embedded in religion-of social capital, of practices and rituals, and of worldview-actually contributed to the increased COVID-19 infection rates among the ultra-Orthodox population. The explanation for this seems to be found in two major factors: (1) The nature of the disease, namely, that the disease is particularly highly contagious in a social setting characterized by the community way of living followed by the ultra-Orthodox society. This lifestyle includes many aspects of the social capital embedded in religion along with collective religious practices and rituals. (2) The nature of ultra-Orthodox society, a society that tends to obey its religious leaders, especially in times of crisis (Brown 2017; Friedman 1991; Heilman and Friedman 2010). Religious leadership is also an integral aspect of religion, which could promote the health of the religious believers (Shapiro et al. 2020; Zalcberg 2014). Yet in this case, not only did many of the ultra-Orthodox religious leaders not contribute to the eradication of the pandemic, they actively gave instructions that contributed to its spread.

It appears that despite the cracks that have formed in recent years in the traditional sources of authority in the ultra-Orthodox communities-namely the rabbis and the Admors (Brown 2017) — most of the ultra-Orthodox people still obey the traditional religious leadership. It also appears that, despite the "Israelization" process that ultra-Orthodox society has been undergoing in recent years (Caplan and Stadler 2009), there is still a certain level of suspicion and lack of trust towards the State and its institutions. This level of suspicion varies among the various sub-communities, and it does not only exist among the zealots sects. On the part of the state authorities, it seems that they did not supply relevant culturally adapted clear information in real time for the ultra-Orthodox population, regarding the disease, its symptoms and ways to prevent its spread.

An overview of these findings showed that an examination of the ultra-Orthodox population's health behaviors during the first months of the COVID-19 could serve as a prism for understanding ultra-Orthodox society and the relationship between this society and the surrounding Israeli society. On a broader level, the findings of 
the study indicated that health behaviors of a minority group might reflect characteristics of the group, as well as the group's relations with the majority society.

In light of the insights gained in this study, it is recommended that state authorities deal with the infection rates among the ultra-Orthodox sector in accordance with the specific conduct of each community, rather than regarding the entire ultraOrthodox population as one homogenous group. Attention should be given for culturally sensitive conduct on the part of state authorities towards the ultra-Orthodox population and its sub-communities (Coleman Brueckheimer and Dein 2011; Shapiro 2018), while also increasing the accessibility of information about COVID-19 and adjusting the conditions of the COVID-19 facilities to ultra-Orthodox patients' needs, according to particular ultra-Orthodox values and norms. Culturally adapted health interventions that comply with the values of the ultra-Orthodox population have proven to be effective in various fields of welfare and health (Coleman Brueckheimer and Dein 2011; Greenberg and Witztum 2013; Band-Winterstein and Freund 2015), and it is quite possible that they will prove to be effective in the fight against COVID-19 as well.

Due to the importance of religious authority in ultra-Orthodox society, and the social significance of obeying religious authority figures, it is also recommended that state authorities cooperate with the religious leadership in circumventing the spread of COVID-19 amongst the ultra-Orthodox, rather than attempt to bypass or challenge religious authority. The literature has shown that collaboration with religious leaders may significantly promote health behaviors and the overall health situation in religious communities (Heward-Mills et al. 2018; Saban et al. 2020). Such collaboration has proven effective in various health-related aspects amongst the ultra-Orthodox society (Coleman Brueckheimer et al. 2009; Greenberg and Witztum 2013). One of the most prominent examples of this effectiveness was when ultra-Orthodox leadership agreed to encourage people to conduct premarital genetic testing. As time went on, these tests became routine in the ultra-Orthodox community and has led to the almost total elimination of illnesses that can be detected by genetic testing (Zalcberg Block 2014). Further, participants emphasized the importance of the religious value that states, "you should take great care for your souls," i.e., maintain good health; this strengthens the argument that there is room for collaboration between state authorities and the religious leadership in ultra-Orthodox society, in the general health field, and in particular in the battle against COVID-19.

Despite the insights gained from the current study, the study has several limitations. First, the study was based on a small sample of 25 participants, whose willingness to participate in and of itself might point to shared characteristics among the sample that may have influenced their perceptions and behaviors during the COVID19 period. In addition, the sample did not include ultra-Orthodox Sephardim. Thus, there may be additional voices and perspectives in ultra-Orthodox society that were not captured in the current study due to the character of the sample. Second, the limited scope of the sample did not allow for conducting quantitative analyses, and thus there are no analyses that differentiated between participants according to sociodemographic variables such as economic status, education, gender and their sub-sectorial group belonging. It is quite possible that these sociodemographic characteristics influenced participants' perceptions concerning the matters discussed. Therefore, it 
is recommended that future research will be based on a broader sample, which will thereby also include ultra-Orthodox Sephardim, and a larger sample which would enable quantitative analyses. Such analyses could provide additional information about differences between the subgroups of ultra-Orthodox society and may help to validate the findings of the current study, or, alternatively, challenge them.

Due to the important role of the religious leadership under the current circumstances, a follow-up study about the personal views of the ultra-Orthodox leaders might supply useful information for culturally adapted interventions. In addition, it will be interesting to learn whether ultra-Orthodox people's views of their leaders as sources of unquestioned guidance have changed because of their recent experience during the COVID-19 period; whether there were expressions of doubts or even resistance relating to the Da' as Torah/Emunas Chachamim models of "subservience"; and whether the pandemic has changed people's faith.

Moreover, the dynamic nature of the COVID-19 pandemic, and as a result the shifting governmental instructions intended to battle it, affects the conduct of the ultra-Orthodox population, which may change from one week to the next and sometimes from one day to the next. Thus, it is important to emphasize that the findings of the current study reflect the situation and experiences within ultra-Orthodox society only up until the time that the study was conducted-the first 6 months of the COVID-19 outbreak in Israel. Therefore, it is strongly recommended to conduct a follow-up study that examines this issue over time and provides a more comprehensive and up-to-date description of the situation.

As ultra-Orthodox all over the world share some of the major characteristics of Israeli ultra-Orthodox, similar research among ultra-Orthodox in other countries would be helpful and might shed light on some of the discussed issues in this paper.

Acknowledgements Funding was provided by Shandong University - Tel Aviv University Joint Institute for Jewish and Israel Studies.

\section{References}

Alfasi, Nurit, Flint Shlomit, and Itzhak Benenson. 2013. Between the individual and the community: Residential patterns of the Haredi population in Jerusalem. Localización International Journal of Urban and Regional Research 37(6): 2152-2176. https://doi.org/10.1111/j.1468-2427.2012.01187.x.

American Psychological Association. 2002. Ethical principles of psychologists and code of conduct. American Psychologist 57(12): 1060-1073.

Katja, Katja, Jutta Roosen, and Helen H. Jensen. 2016. Poverty dynamics in Germany: Evidence on the relationship between persistent poverty and health behavior. Social Science \& Medicine 153: 62-70. https://doi.org/10.1016/j.socscimed.2016.01.040.

Band-Winterstein, Tova, and Anat Freund. 2015. Is it enough to 'speak Haredi'? Cultural sensitivity in social workers encountering Jewish ultra-orthodox clients in Israel. The British Journal of Social Work 45(3): 968-987. https://doi.org/10.1093/bjsw/bct167.

Bayram, Tevfik, and Milka Donchin. 2019. Determinants of health behavior inequalities: A cross-sectional study from Israel. Health Promotion International 34(5): 941-952. https://doi.org/10.1093/ heapro/day054.

Ben-Yehuda, Nachman. 2010. Theocratic democracy. New York: Oxford University Press. 
Braun-Lewensohn, Orna, and Thila Kalagy. 2019. Between the inside and the outside world: coping of ultra-orthodox individuals with their work environment after academic studies. Community Mental Health Journal 55(5): 894-905.

Brown, Benjamin. 2017. The Haredim. A Guide to their Beliefs and Sectors. Jerusalem: The Israeli Democracy Institute [Hebrew].

Cahaner, Lee, \& Gilad. Malach. 2019. Statistical report on Orthodox Society in Israel 2018. Center for Religion, Nation and State. The Jerusalem Institute for Policy Research. Jerusalem.

Caplan, Kimi. 2017. Amram Blau: The World of Neturei Karta's Leader. Jerusalem: Yad Ben Zvi and Ben Gurion University of the Negev [Hebrew].

Caplan, Kimi \& Nurit Stadler (eds.). 2009. Leadership and Authority in Israeli Haredi Society. Tel-Aviv: H'akibutz H'ameuhad and the Van Leer Institute [Hebrew].

Cheng, Tina L., and Elizabeth Goodman. 2015. Race, ethnicity, and socioeconomic status in research on child health. Pediatrics 135(1): 225-237. https://doi.org/10.1542/peds.2014-3109.

Chernichovsky, Dov, and Chen Sharony. 2015. The relationship between social capital and health in the Haredi sector. In The State of the Nation Report 2015 Jerusalem, December 2015, ed. D. Chernichovsky and A. Weiss, 356-469. Jerusalem: Taub Center for Social Policy Studies (in Israel).

Coleman Brueckheimer, Kate, and Simon Dein. 2011. Health care behaviors and beliefs in Hasidic Jewish populations: A systematic review of the literature. Journal of Religion and Health 50(2): 422436. https://doi.org/10.1007/s10943-010-9448-2.

Coleman Brueckheimer, Kate, Joseph Spitzer, and Jonathan Koffman. 2009. Involvement of Rabbinic and communal authorities in decision-making by Haredi Jews in the UK with breast cancer: An interpretative phenomenological analysis. Social Science and Medicine 68: 323-333. https://doi.org/10. 1016/j.socscimed.2008.10.003.

Corbin, Juliet, and Anselm Strauss. 2015. Basics of qualitative research: Techniques and procedures for developing grounded theory. Thousand Oaks: Sage Publications.

Denzin, Norman K., and Yvonna S. Lincoln. 2011. Handbook of Qualitative Research. Thousand Oaks: Sage Publications.

Elgar, Frank J., Geneviève Gariépy, Torbjørn Torsheim, and Candace Currie. 2017. Early-life income inequality and adolescent health and well-being. Social Science \& Medicine 174: 197-208. https:// doi.org/10.1016/j.socscimed.2016.10.014.

Emmel, Nick. 2013. Purposeful sampling. In Emmel, N. Sampling and choosing cases in qualitative research: A realist approach (pp. 33-44).

Eriksson, Malin. 2011. Social capital and health: Implications for health promotion. Global Health Action. 4: 1. https://doi.org/10.3402/gha.v4i0.5611.

Frei-Landau, Rivi. 2020. "When the going gets tough, the tough get-Creative": Israeli Jewish religious leaders find religiously innovative ways to preserve community members' sense of belonging and resilience during the COVID-19 pandemic. Psychological Trauma: Theory, Research, Practice, and Policy 12(S1): S258-S260. https://doi.org/10.1037/tra0000822.

Fisher, Shlomo. 2020. Religion and class: Theoretical and research directions. Megamot 55(1): 25-50.

Friedman, Menachem. 1991. Ultra-Orthodox Society: Sources trends and processes. Jerusalem: Jerusalem Institute for Israel Studies [Hebrew].

Friedman, Menachem. 2002. Haredi violence in contemporary Israeli society. Studies in Contemporary Jewry 18: 186-197.

Greenberg, David, and Eliezer Witztum. 2013. Challenges and conflicts in the delivery of mental health services to ultra-orthodox Jews. Asian Journal of Psychiatry 6(1): 71-73.

Hanau, Shira. 2020. www.jpost.com/israel-news/one-in-every-132-haredim-over-65-in-israel-has-diedfrom-coronavirus-653665

Heidari, Saeide, Mahboubeh Rezaei, Mahbobeh Sajadi, Neda Mirbagher Ajorpaz, and Harold G. Koenig. 2017. Religious practices and self-care in Iranian patients with type 2 diabetes. Journal of Religion and Health 56(2): 683-696. https://doi.org/10.1007/s10943-016-0320-x.

Heilman, S. 2000. Defenders of the faith. University of California Press.

Heilman, S., and M. Friedman. 2010. The Rebbe: The life and afterlife of Menachem Mendel Schneerson. Princeton University Press.

Heward-Mills, Nii L., Catherine Atuhaire, Chris Spoors, Ngambouk Vitalis, and Samuel Nambile Cumber. 2018. The role of faith leaders in influencing health behaviour: a qualitative exploration on the views of Black African Christians in Leeds, United Kingdom. Pan African Medical Journal 30: 199. https://doi.org/10.11604/pamj.2018.30.199.15656. 
Idler, Ellen J., John Blevins, Mimi Kiser, and Carol Hogue. 2017. Religion, a social determinant of mortality? A 10-year follow-up of the Health and Retirement Study. PLoS ONE 12(12): e0189134. https://doi.org/10.1371/journal.pone.0189134.

Idler, Ellen J., and Allan Kellehear. 2017. Religion in public health-care institutions: US and UK perspectives. Journal for the Scientific Study of Religion 56(2): 234-240. https://doi.org/10.1111/jssr.12349.

Kail, Ben L., Amy Spring, and Matt Gayman. 2019. A conceptual matrix of the temporal and spatial dimensions of socioeconomic status and their relationship with health. The Journals of Gerontology. B 74(1): 148-159. https://doi.org/10.1093/geronb/gby025.

Kasir, Nitsa, Dmitri Romanov, and D. Romanov. 2017. Quality of life among Israel's population groups. Jerusalem: The Haredi Institute for Public Affairs.

Krause, Neal. 2016. Assessing the relationships among religiousness, loneliness, and health. Archive for the Psychology of Religion 38(3): 278-300. https://doi.org/10.1163/15736121-12341330.

Leiter, E., A. Finkelstein, K. Greenberg, O. Keidar, M. Donchin, and D.R. Zwas. 2019. Barriers and facilitators of health behavior engagement in ultra-Orthodox Jewish women in Israel. European Journal of Public Health. 29(4): ckz186.455. https://doi.org/10.1093/eurpub/ckz186.455.

Levin, Jeff. 2016. Partnerships between the faith-based and medical sectors: Implications for preventive medicine and public health. Preventive Medicine Reports 4: 344-350. https://doi.org/10.1016/j. pmedr.2016.07.009.

Levin, Jeff, L.M. Chatters, and R.J. Taylor. 2011. Theory in religion, aging, and health: An overview. Journal of Religion and Health 50(2): 389-406. https://doi.org/10.1007/s10943-009-9319-x.

Lincoln, Yvonna S., and Egon G. Guba. 1985. Naturalistic inquiry. Newbury Park, CA: Sage.

Malach, Gilad, and Lee Cahaner. 2017. Elements of modern life or "modern ultra-orthodoxy"? Numerical assessment of modernization processes in ultra-orthodox society. Democratic Culture 17: 19-51 ([Hebrew]).

Malach, Gilad., and Lee Cahaner. 2020. Statistical report on Orthodox Society in Israel 2019. Center for Religion, Nation and State. The Jerusalem Institute for Policy Research. Jerusalem.

Milstein, Glen, Roman Palitsky, and Adolfo Cuevas. 2020. The religion variable in community health promotion and illness prevention. Journal of Prevention \& Intervention in the Community 48(1): $1-6$.

Muhsen, Khitam, Manfred S. Green, Varda Soskolne, and Yehuda Neumark. 2017. Inequalities in noncommunicable diseases between the major population groups in Israel: Achievements and challenges. The Lancet 389(10088): 2531-2541. https://doi.org/10.1016/S0140-6736(17)30574-3.

Ofstedal Beth, Mary, Chi-Tsun. Chiu, Carol Jagger, Yasuhiko Saito, and Zachary Zimmer. 2019. Religion, life expectancy, and disability-free life expectancy among older women and men in the United States. The Journals of Gerontology 74(8): e107-e118. https://doi.org/10.1093/geronb/gby098.

Peles, Chagit, Mary Rudolf, and Michael Weingarten. 2018. What can be learned from health-related tensions and disparities in ultra-orthodox Jewish families? Journal of Religion \& Health 57: 11331145. https://doi.org/10.1007/s10943-018-0590-6.

Pinchas-Mizrachi, Ronit, Beth G. Zalcman, and Ephraim Shapiro. 2020. Differences in mortality rates between Haredi and non-Haredi Jews in Israel in the context of social characteristics. Journal for the Scientific Study of Religion. https://doi.org/10.1111/jssr.12699.

Pinchas-Mizrachi, R., A. Solnica, and N. Daoud. 2020. Religiosity level and mammography performance among Arab and Jewish women in Israel. Journal of Religion and Health. https://doi.org/10.1007/ s10943-020-01097-2.

Raifman, Matthew A., and Julia R. Raifman. 2020. Disparities in the population at risk of severe illness from COVID-19 by race/ethnicity and income. American Journal of Preventive Medicine 59(1): 137-139. https://doi.org/10.1016/j.amepre.2020.04.003.

Saban, Mor, Vicki Myers, and Rachel Wilf-Miron. 2020. Coping with the COVID-19 pandemic: The role of leadership in the Arab ethnic minority in Israel. International Journal for Equity in Health 19: 1-6. https://doi.org/10.1186/s12939-020-01257-6.

Satariano, Bernadine. 2020. Religion, health, social capital and place: The role of the religious, social processes and the beneficial and detrimental effects on the health and wellbeing of inhabitants in deprived neighborhoods in Malta. Journal of Religion and Health 59: 1161-1174. https://doi.org/ 10.1007/s10943-020-01006-7.

Shapiro, Ephraim. 2018. Places of habits and hearts: Church attendance and Latino immigrant health behaviors in the United States. Journal of Racial and Ethnic Health Disparities 5(6): 1328-1336. https://doi.org/10.1007/s40615-018-0481-2. 
Shapiro, Ephraim, and Chen Sharony. 2018. Religious and social capital and health. In Elgar companion to social capital and health, ed. E. Elagar, 70-88. Edward Elgar Publishing.

Shapiro, Ephraim, Livia Levine, and Avi Kay. 2020. Mental health stressors in Israel during the coronavirus pandemic. Psychological Trauma: Theory, Research, Practice, and Policy 12(5): 499-501. https://doi.org/10.1037/tra0000864.

Tsachor-Shai, Assaf, and Nitsa Kasir. 2020. Covid-19, Crowding and Haredi Cities. Jerusalem: The Haredi Institute for Public Affairs.

VanderWeele, Tyler J. 2017. Religion and health: A synthesis. In M.J. Balboni, \& J.R. Peteet (Eds.). Spirituality and Religion within the culture of Medicine: From evidence to practice (pp. 357-401). Oxford University Press.

Weber, Max. 1964. The sociology of religion. Boston: Beacon Press.

Wi, C.I., J.L. St Sauver, D.J. Jacobson, R.S. Pendegraft, B.D. Lahr, E. Ryu, T.J. Beebe, J.A. Sloan, J.L. Rand-Weaver, E.A. Krusemark, Y. Choi, and Y.J. Juhn. 2016. Ethnicity, socioeconomic status, and health disparities in a mixed rural-urban US community-Olmsted County, Minnesota. Mayo Clinic Proceedings 91(5): 612-622.

Zalcberg, Sara. 2013. The silence of males: The significance of sexual assault among male victims from ultra-orthodox (Haredi) background. Phd dissertation. The Hebrew University of Jerusalem. [Hebrew]

Zalcberg, Sara. 2021. Changes in coping patterns of ultra-orthodox society in Israel regarding sexual abuse. In Sexual delinquency: Trends in legislation. Enforcement, assessment and treatment, ed. M. Shhory-Bitton, Y. Aboulafia, and L. Tvi. Jerusalem: Carmel Publishing House. Accepted for publication [Hebrew].

Zalcberg, Sima. 2009. Channels of knowledge and information about menstruation and sexuality among Hasidic Adolescent girls. Nashim: A Journal of Jewish Women's Studies \& Gender Issues 17: 60-88. https://www.jstor.org/stable/10.2979/nas.2009.

Zalcberg Block, S. 2014. Arranged marriages and genetics premarital genetic testing in Haredi society. Studying Haredi Society 2: 24-43 ([Hebrew]).

Zalcberg Block, Sima. 2020. The encounter of religious radicalism, class and gender in Beit Shemesh. Megamot 55(1): 193-224. [Hebrew].

Publisher's Note Springer Nature remains neutral with regard to jurisdictional claims in published maps and institutional affiliations.

Sara Zalcberg received both her BA and her MA in criminology from Bar Ilan University. She received her PhD in sociology from the Hebrew University of Jerusalem. She is an Adjunct Lecturer at Tel-Aviv University (Religious Studies) and at the Hebrew University (School of Social Work and Social Welfare), Israel. Her research fields are religion, gender and sexuality; deviance, sexual abuse and child abuse; Jewish ultra-Orthodox society and multiculturalism.

Sima Block received both her BA in social work and her Ph.D. in sociology from Bar Ilan University; in between she earned her MSc from the Technion-Israel Institute of Technology. She is a Senior Teacher at Ariel University (School of Social Work), and an Adjunct Lecturer at Tel-Aviv University (Religious Studies) and at the Hebrew University (School of Social Work and Social Welfare), Israel. Her research fields are gender, religion, religious fanaticism, and sexuality; Hasidism; Jewish ultra-Orthodox society, multiculturalism and ethnography. 